\title{
Construction of an RF Quadrupole Magnet for Suppressing
}

\section{Transverse Coupled-Bunch Instabilities}

\author{
Shogo Sakanaka and Toshiyuki Mitsuhashi \\ Photon Factory, National Laboratory for High Energy Physics (KEK) \\ 1-1 Oho, Tsukuba-shi, Ibaraki-ken 305 Japan
}

\section{Abstract}

An RF Quadrupole Magnet (RFQM), which can produce a split in betatron tunes between individual bunches, was developed and effects on transverse coupled-bunch instabilities were investigated. The instability thresholds were raised by the use of the RFQM.

\section{INTRODUCTION}

Coupled-bunch instabilities arising from high coupling impedances of accelerating cavities cause a current limitation in multi-bunch machines. One of the cures for transverse coupled-bunch instabilities is to introduce a spread in betatron frequencies of individual bunches in order to destroy the coherence of the coupled oscillations[1-4]. It was reported that this cure was applied in DORIS, resulting in an increase of the instability threshold[1]. However, we cannot find any report on a detailed study on it nor on a hardware. So we developed a new device "RFQM" which can produce the bunch-to-bunch tune spread. We installed the RFQM in the Photon Factory $2.5 \mathrm{GeV}$ positron storage ring ( $\mathrm{PF}$ ring) at $\mathrm{KEK}$, and made a detailed study. The hardware and the results are described in this paper.

\section{HARDWARE}

The RFQM system can provide a quadrupole magnetic-field oscillating at the revolution frequency of the PF ring (1.6 $\mathrm{MHz}$ ). The principle parameters are given in Table 1. It consists of a magnet, a ceramic duct and a power supply.

\section{A. RF Quadrupole Magnet}

The RFQM was designed by the use of a computer code POISSON[5]. As shown in Figs. 1 and 2, the RFQM has a

Table 1. Principle parameters of the RF quadrupole magnet.

$\begin{array}{ll}\text { Maximum field gradient (pcak valuc) } & 0.0173 \mathrm{~T} / \mathrm{m} \\ \text { Maximum peak current } & 43 \mathrm{~A} \\ \text { Excitation frequency } & 1.6029 \mathrm{MHz} \\ \text { Bore diameter } & 120 \mathrm{~mm} \\ \text { Core length } & 0.34 \mathrm{~m} \\ \text { Effective magnetic length } & 0.38 \mathrm{~m} \\ \text { Self inductance } & 2.1 \mu \mathrm{H} \\ \text { Maximum output power of RF amp } & 2 \mathrm{~kW} \\ \text { Maximum horizontal tune shift (peak value) } & 1.23 \times 10^{-3} \\ \text { Maximum vertical tune shift (peak value) } & 6.8 \times 10^{-4}\end{array}$

one-turn coil and a ferrite yoke. We adopted a flat shape for magnet poles to make the fabrication easy. The magnet can be devided into upper and lower pieces for the requirement of setting the ceramic duct in it.

A field distribution inside the RFQM was measured with a search coil of $3 \mathrm{~mm}$ in diameter. An output signal from the coil was calibrated with a standard coil by the use of a dipole magnet. We obtained a field gradient of $0.0173 \mathrm{~T} / \mathrm{m}$ at a peak current of $43 \mathrm{~A}$; the measured field-gradient was $6 \%$ larger than the calculated value.

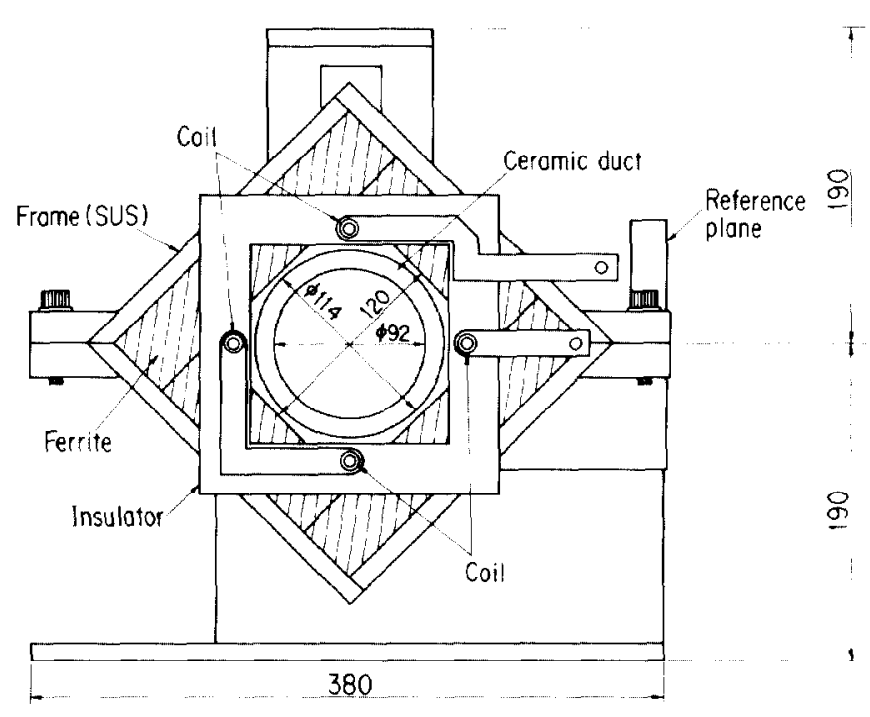

Fig. 1. Front view of the RF quadrupole magnet.

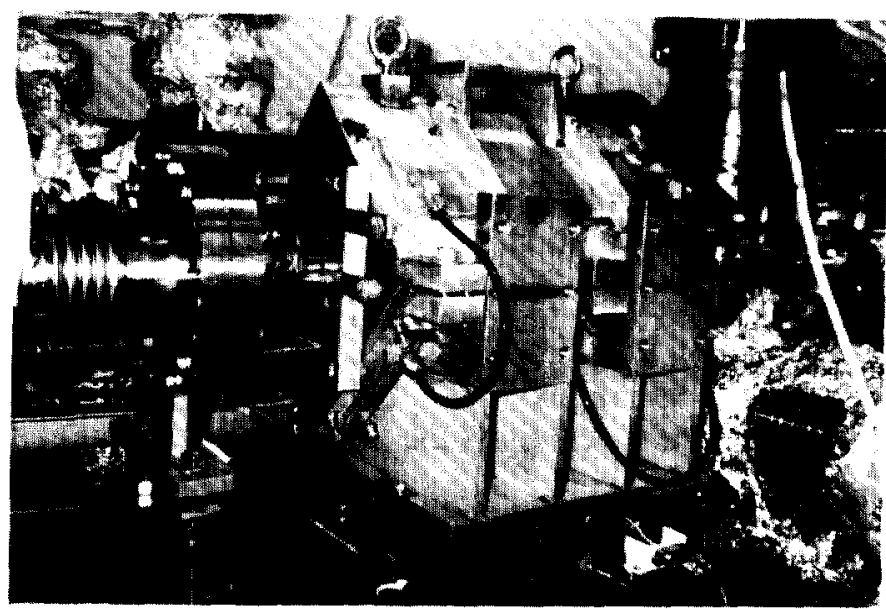

Fig. 2. Photograph of the RFQM installed in the PF ring. 
A quadrupole center of the RFQM was aligned to the beam orbit within $\sim 0.5 \mathrm{~mm}$. In addition, the RFQM was put on a movable horizontal-vertical stage which allowed us to adjust the position during ring operations.

\section{B. Ceramic Duct}

A ceramic duct, shown in Fig. 3, was adopted to avoid problems due to eddy currents. In order to reduce a beamcoupling impedance, inner and outer sides of the duct were coated with titanium stripes of $1.4 \mu \mathrm{m}$ thick; this configuration allowed us to prevent the coating from heatingup due to eddy currents. The inner-side stripes were connected with the left-side kovar flange (see Fig. 3), while the outerside stripes the right-side kovar flange, in order to cut the currents induced by the RFQ-field. Then, high frequency components of the wall current flow through a capacitor between the inner and outer stripes. Low frequency components flow through a bypass conductor bridged over the RFQM. The duct caused no problems in both single and multi bunch operations. Temperature of the duct was raised up to $40^{\circ} \mathrm{C}$ when the maximum field was applied, and up to $70^{\circ} \mathrm{C}$ when a single bunch beam of $50 \mathrm{~mA}$ was stored.

An absorber was placed upstream the RFQM in order to prevent the synchrotron radiation from impinging on the duct.
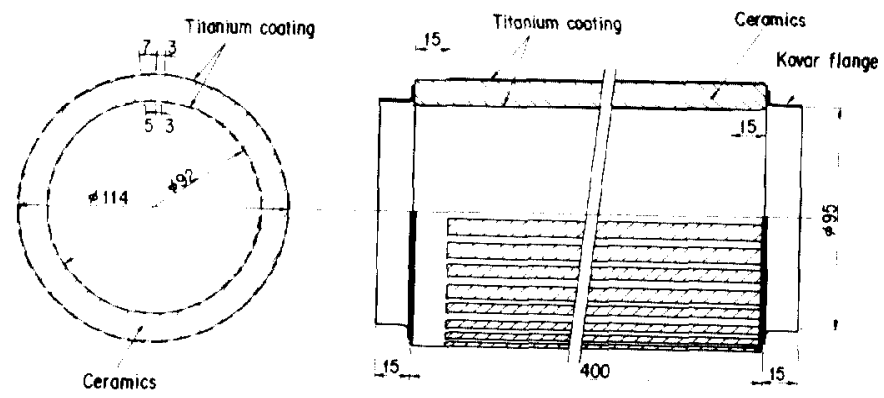

Fig. 3. Ceramic duct coated with titanium stripes.

\section{Power Supply}

A block diagram of the power supply is shown in Fig. 4. A sinusoidal signal synchronized to the beam revolution is input to a power amplifier. The output from the amplifier is fed to a parallel resonance circuit including the RFQM through an impedance matching circuit. The RFQM is driven by the resonance current.

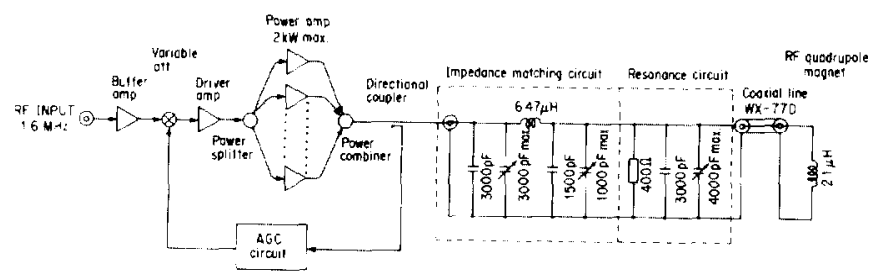

Fig. 4. Block diagram of the RFQM power supply.

\section{STUDIES WITH BEAMS}

\section{A. Measurement of tune shifts produced by the RFQM}

We measured tune shifts produced by the RFQM with a single bunch beam by changing the phase of the RFQ-field against the beam revolution signal. The result of the measurement is shown in Fig. 5. We obtained maximum tune shifts of $1.23 \times 10^{-3}$ (hor.) and $6.8 \times 10^{-4}$ (ver.).

Betatron tune distributions in a multi-bunch operation were also measured, and we observed splits in betatron tunes while the RFQM being excited.

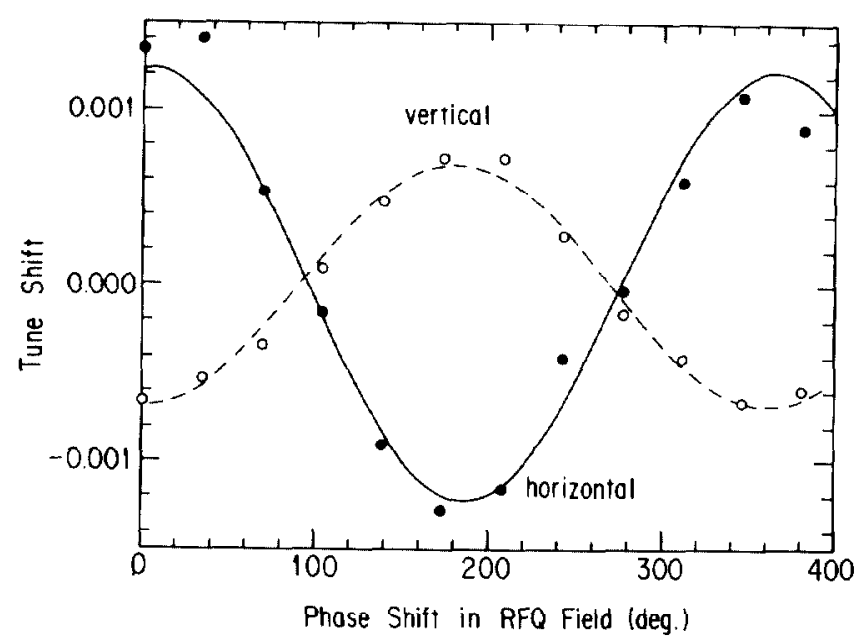

Fig. 5. Measured tune shifts produced by the RFQM in the single bunch operation. Solid and dashed lines denote fitted lines with sinusoidal curves. Peak current of the RFQM: $43 \mathrm{~A}$.

\section{B. Effects of the bunch-to-bunch tune spread on a horizontal coupled-bunch instability caused by TMI11(H)-mode}

In the PF ring, several coupled-bunch instabilities arising from higher-order-mode (HOM) resonances of the cavities have been observed. Though these instabilities are routinely avoided by a careful trimming of the HOM frequencies[6], they can be produced by tuning the HOM frequencies appropriately.

We first studied the effect of the RFQ-field on a horizontal instability caused by $\mathrm{TM} 11 \mathrm{l}(\mathrm{H})$-mode. In order to induce this instability, a resonant frequency of the TM111(H)-mode of one of four cavities was tuned to the frequency of $\left(669-\delta v_{X}\right) f_{r}$, where $\delta v_{X}$ is a fractional part of the horizontal tune $\left(\delta v_{x}\right.$ was 0.4518 in the experiment) and $\mathrm{f}_{\mathrm{r}}$ is the revolution frequency; the tuning was made by adjusting a position of a tuning plunger of the cavity which was not powered.

We measured the threshold currents with three different excitation currents of the RFQM by slightly changing the resonant frequency; we intended to investigate the effects of the RFQM on the instability driven not only by a purely resistive impedance but also by an impedance having a large reactive part. The result is shown in Fig. 6. 


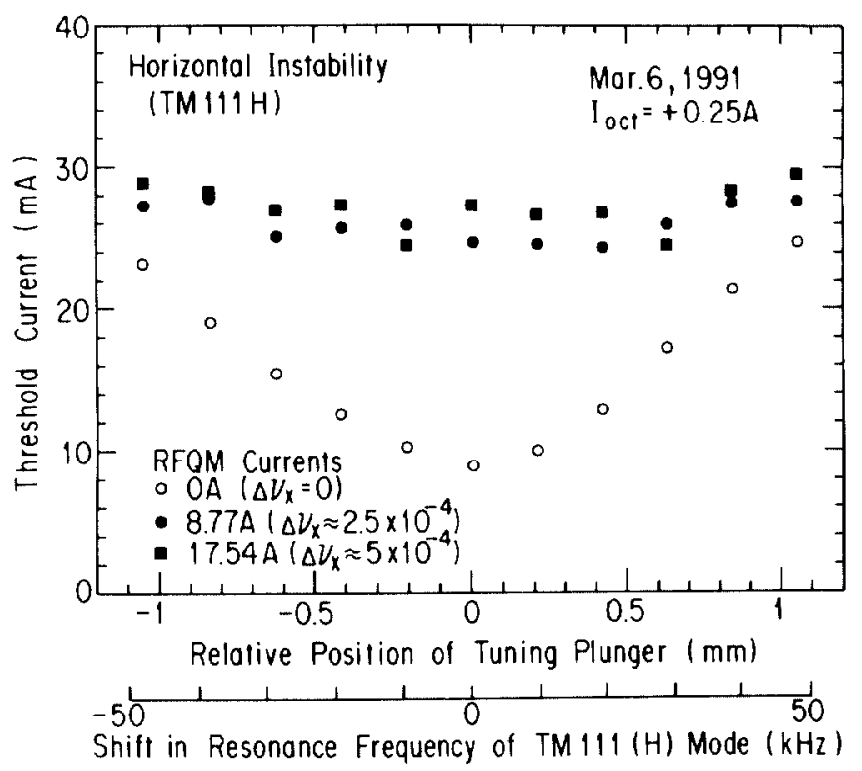

Fig. 6. Threshold currents of the TM111(H) instability with three different cases of the RFQM current. The data are shown as a function of the shift in the resonant frequency of the TM111(H) mode. The frequency at the center of abscissa, loaded- $Q$ value and calculated $\mathrm{RT}_{\mathrm{T}} / \mathrm{Q}$ of the TM111(H) mode were $1071.62 \mathrm{MHz}$ $\left(\approx\left(669-\delta v_{X}\right) f_{Y}\right), 13,000$, and $675 \Omega / m$, respectively. The transverse radiation damping time was $7.8 \mathrm{~ms}$. The ring was uniformly filled.

It was found that: 1) without exciting the RFQM, the minimum threshold current of $9.0 \mathrm{~mA}$ was obtained when the resonanct frequency was tuned to $\left.\approx\left(669-\delta v_{X}\right) f_{r} ; 2\right)$ at that frequency, the threshold current increased by a factor of 2.7 by introducing the tune spread of $2.5 \times 10^{-4}$ (peak value); 3) increases in the threshold became small as the frequency was detuned from $\left(669-\delta v_{x}\right) f_{r}$. These results suggested that the RFQM was effective on the instability which was driven by a purely resistive impedance, while it was less effective when the instability was driven by an impedance which had a large reactive part. This result is qualitatively in agreement with the theory presented by Chin and Yokoya[4].

\section{Effect on a vertical instability}

In the PF ring, a vertical instability which leads to an increase of a beam size at high currents has been observed[7]. The principle features of this instability are: 1) the threshold current is about $18 \mathrm{~mA}$ with octupole magnets off; 2) observed only with positron beams; 3 ) it is accompanied with several betatron spectrum lines distributed over about 15 times the revolution frequency. The cause of this instability is not yet understood. We measured the threshold currents of the instability as a function of the RFQM current. The result is shown in Fig. 7. An increase in the threshold was only a factor of 1.2 with the maximum tune spread.

\section{CONCLUSION}

Effects of the bunch-to-bunch tune spread on the coupledbunch instabilities were investigated in detail. We observed

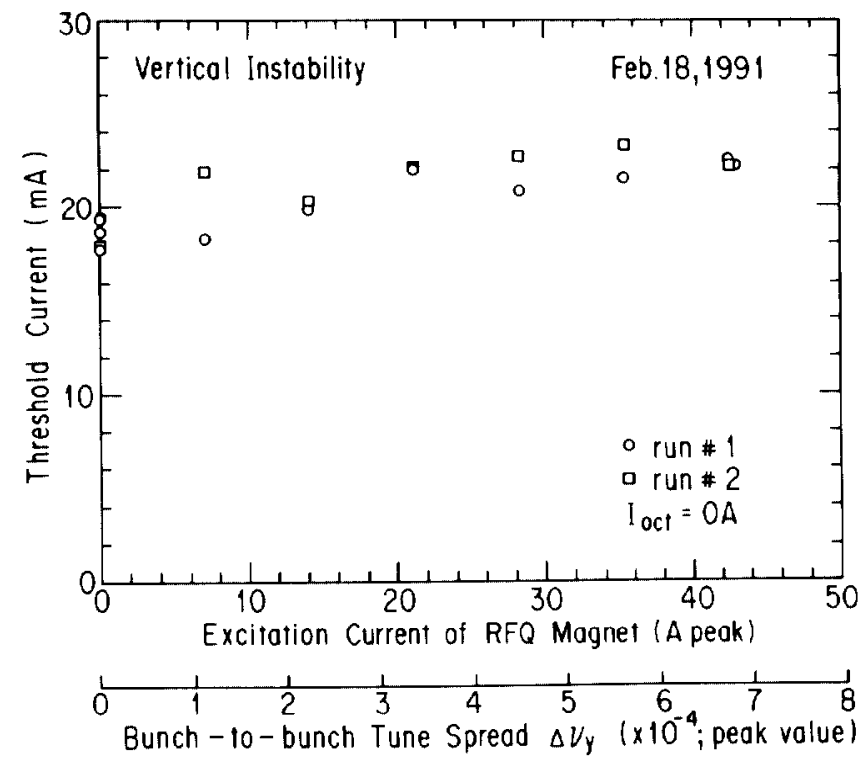

Fig. 7. Dependence of the threshold currents of the vertical instability on the excitation current of the RFQM. The ring was uniformly filled.

increases in the threshold currents in both TM111(H) instability and in the vertical instability. More quantitative analysis of the results is in progress.

\section{Acknowledgement}

The authors wish to express their gratitude to T. Shintake, K. Yokoya, T. Yamakawa, Y. Kamiya, M. Kobayashi and S. Ninomiya for helpful discussions and suggestions, to $Y$. Hori and $Y$. Takiyama for remodelling the ring for the installation of the RFQM and to M. Izawa and A. Ueda for their help in the studies. We also wish to thank H. Kobayakawa for promoting our work.

\section{REFERENCES}

[1] R.D. Kohaupt, "SINGLE BEAM INSTABILITIES IN DORIS", IEEE Trans. Nucl. Sci., NS-22, pp. 1456-1457, 1975.

[2] G. Saxon, "IMPLICATIONS OF TRANSVERSE INSTABILITY CRITERIA IN THE DESIGN OF HIGH CURRENT, MULTIBUNCH ELECTRON STORAGE RINGS", Daresbury Laboratory, Report No. DL/SCI/P 204A, October 1979.

[3] Y. Kamiya, "ON SOME PROPERTIES OF LONGITUDINAL AND TRANSVERSE COUPLED-BUNCH INSTABILITIES", KEK, Report No. KEK 82-15, February 1983.

[4] Y.H. Chin and K. Yokoya, "Landau Damping of a Multi-Bunch Instability due to Bunch-to-Bunch Tune Spread", DESY, Report No. DESY 86-097, August 1986.

[5] M.T. Menzel, H.K. Stokes. "User's Guide for the POISSON/SUPERFISH Group of Codes", Los Alamos National Laboratory, Report No. LA-UR-87-115, January 1987.

[6] H. Kobayakawa, M. Izawa, S. Sakanaka and S. Tokumoto, "Suppression of beam instabilities induced by accelerating cavities", Rev. Sci. Instrum., 60, pp. 1732-1735, 1989.

[7] S. Sakanaka, PHOTON FACTORY ACTIVITY REPORT \#7, KEK, pp. R-7 - R-8, 1989. 